\title{
Detection of apical hypertrophic cardiomyopathy; which is the appropriate imaging modality
}

\author{
E. E. van der Wall · J. J. Bax · M. J. Schalij
}

Published online: 1 July 2008

(C) The Author(s) 2008

Apical hypertrophic cardiomyopathy is a form of hypertrophic cardiomyopathy localized to the left ventricular apex. The disease is common in Japanese and other Asian populations but its presence has also been recognized, though less commonly, in non-Asian patients. Its prognosis is relatively benign in terms of cardiovascular mortality but morbid sequelae, such as diastolic dysfunction, left atrial enlargement, apical thrombi, ventricular aneurysms, and myocardial infarction, may occur. In patients with apical hypertrophic cardiomyopathy, the electrocardiographic changes and symptoms associated often mimic acute coronary syndromes. Invasive or noninvasive evaluation of the left ventricular cavity confirms the diagnosis of apical hypertrophic cardiomyopathy, with the "ace-ofspades" sign on left ventriculography being pathognomonic. It is therefore of utmost importance to use the appropriate imaging modalities to establish the correct diagnosis of apical hypertrophic cardiomyopathy. For instance, using doppler-echocardiography in 182 patients with apical hypertrophic cardiomyopathy, three morphologically distinct phenotypes i.e. (1) pure focal, (2) pure diffuse, and (3) a mixed type according to patterns of hypertrophy could be discerned [1]. Detailed subtyping turned out to be important in the prediction of

E. E. van der Wall $(\varangle)$ · J. J. Bax · M. J. Schalij Department of Cardiology, Leiden University Medical Center, Albinusdreef 2, 2333, ZA, Leiden,

The Netherlands

e-mail: E.E.van_derWall@lumc.nl development of atrial fibrillation, left atrial volume index and left ventricular longitudinal function.

In the current edition of this issue, Duygu et al. [2] studied 17 patients with chest pain who had a prediagnosis of coronary artery disease but a final diagnosis of apical hypertrophic cardiomyopathy. Interestingly, all patients showed typical spade-like appearance of the left ventricle by contrast ventriculography and giant negative $\mathrm{T}$-waves on the electrocardiogram. Transthoracic echocardiography showed a maximum wall thickness of $18 \pm 4 \mathrm{~mm}$ and a mean gradient of $30 \mathrm{mmHg}$ by Doppler echocardiography. None of the patients showed significant coronary artery disease; four patients showed myocardial bridging. The authors recommended that the diagnosis of apical hypertrophic cardiomyopathy should always be considered in certain patients with typical anginal symptoms and outspoken negative $\mathrm{T}$ waves on the electrocardiogram. As a result, physicians caring for patients with chest pain should consider apical hypertrophic cardiomyopathy in their differential diagnosis in case of a patient with chest pain and electrocardiographic changes suggestive of coronary artery disease. Stated by the authors, these patients should all undergo echocardiography to separate apical hypertrophic cardiomyopathy from acute myocardial ischemia. Although the authors mention that ischemic evaluation was not performed, they only refer to thallium myocardial scintigraphy as potential modality to identify ischemia in apical hypertrophic cardiomyopathy. Indeed, myocardial scintigraphy 
using perfusion tracers and metabolic markers have shown to be useful in the evaluation of cardiomyopathies [3-6].

It is, however, noteworthy that the authors did not refer to cardiac magnetic resonance imaging (CMR) as an accurate and reliable means of evaluating cardiac morphology, ventricular function, and myocardial perfusion, both for the left and the right ventricle therewith covering a whole spectrum of cardiac diseases [7-12]. In particular, CMR is very well suited for identifying and characterizing patients with hypertrophic cardiomyopathy [13, 14]. For instance, Tsukamoto et al. [15] showed systolic outward motion of the left ventricular apical wall in patients with apical hypertrophic cardiomyopathy using CMR tagging. In addition, CMR allows accurate evaluation of myocardial ischemia and infarction with the potential to establish the transmural extent of myocardial infarction with high spatial resolution [16-18]. Late gadolinium-enhanced CMR can clearly delineate subendocardial infarction and CMR appears to be more sensitive than other imaging methods in detecting small infarcts and ischemia [19-21]. In recent years, late gadolinium enhancement CMR has also been used to visualize myocardial interstitial abnormalities in patients with different forms of cardiomyopathies [22, 23]. In patients with apical hypertrophic cardiomyopathy, first-pass gadolinium delayed-enhanced CMR may show local delayed enhancement in the subendocardium in the hypertrophic lesion. The presence of perfusion defect and delayed enhancement may be a marker of a high-risk patient with apical hypertrophic cardiomyopathy [24]. On the other hand, patients with apical hypertrophic cardiomyopathy may show focal hyperenhancement of the non-hypertrophic basal lateral segment of the left ventricle, and absence of hyperenhancement of the hypertrophied apical segments [25].

It can be concluded that apical hypertrophic cardiomyopathy is a disease that may mimic coronary artery disease in a certain subset of patients. Hence, adequate diagnostic methods are needed to distinguish between these two entities. Although echocardiography remains the first line of investigation in these patients the final answer might be given by CMR.

Open Access This article is distributed under the terms of the Creative Commons Attribution Noncommercial License which permits any noncommercial use, distribution, and reproduction in any medium, provided the original author(s) and source are credited.

\section{References}

1. Choi EY, Rim SJ, Ha JW et al (2008) Phenotypic spectrum and clinical characteristics of apical hypertrophic cardiomyopathy: multicenter echo-Doppler study. Cardiology 110:53-61

2. Duygu H, Zoghi M, Nalbantqil S et al (2008) Apical hypertrophic cardiomyopathy might lead to misdiagnosis of ischaemic heart disease. Int J Cardiovasc Imaging. doi: 10.1007/s10554-008-9311-7

3. Lee KH, Jang HJ, Lee SC et al (2003) Myocardial thallium defects in apical hypertrophic cardiomyopathy are associated with a benign prognosis. Thallium defects in apical hypertrophy. Int J Cardiovasc Imaging 19:381-388

4. Ohtsuki K, Sugihara H, Kunbayashi T, Kakagawa M (1999) Impairment of BMIPP accumulation at junction of ventricular septum and left and right ventricular free walls in hypertrophic cardiomyopathy. J Nucl Med 40:2007-2013

5. van der Wall EE, Heidendal GA, den Hollander W, Westera G, Roos JP (1980) I-123 labeled hexadecenoic acid in comparison with Thallium-201 for myocardial imaging in coronary heart disease. A preliminary study. Eur J Nucl Med 5:401-405

6. van der Wall EE, den Hollander W, Heidendal GA, Westera G, Majid PA, Roos JP (1981) Dynamic myocardial scintigraphy with 123I-labeled free fatty acids in patients with myocardial infarction. Eur J Nucl Med 6:383-389

7. Tulevski II, Van der Wall EE, Groenink M et al (2002) Usefulness of MRI dobutamine stress in asymptomatic and minimally symptomatic patients with decreased cardiac reserve from congenital heart disease. Am J Cardiol 89: 1077-1081

8. Tulevski II, Lee PL, Groenink M et al (2000) Dobutamineinduced increase of right ventricular contractility without increased stroke volume in adolescent patients with transposition of the great arteries: evaluation with magnetic resonance imaging. Int J Cardiovasc Imaging 16:471-478

9. Dodge-Khatami A, Tulevski II, Bennink GB et al (2002) Comparable systemic ventricular function in heal-thy adults and patients with unoperated congenitally corrected transposition using MRI dobutamine stress testing. Ann Thorac Surg 73:1759-1764

10. Tulevski II, Zijta FM, Smeijers AS et al (2004) Regional and global right ventricular dysfunction in asymptomatic or minimally symptomatic patients with congenitally corrected transposition of the great arteries. Cardiol Young 14: $168-173$

11. Oosterhof T, Mulder BJM, Vliegen HW, De Roos A (2006) Cardiovascular magnetic resonance in the follow-up of patients with corrected tetralogy of Fallot: a review. Am Heart J 151:265-272

12. Tulevski II, Hirsch A, Dodge-Khatami A et al (2003) Effect of pulmonary valve regurgitation on right ventricular function in patients with chronic right ventricular pressure overload. Am J Cardiol 92:113-116

13. Posma JL, van der Wall EE, Blanksma PK, van der Wall E, Lie KI (1996) New diagnostic options in hypertrophic cardiomyopathy. Am Heart J 132:1031-1041

14. Posma JL, Blanksma PK, van der Wall EE, Hamer HP, Mooyaart El, Lie KI (1996) Assessment of quantitative 
hypertrophy scores in hypertrophic cardiomyopathy: magnetic resonance imaging versus echocardiography. Am Heart J 132:1020-1027

15. Tsukamoto M, Hirasaki S, Kuribayashi T et al (2006) Systolic outward motion of the left ventricular apical wall as detected by magnetic resonance tagging in patients with apical hypertrophic cardiomyopathy. J Cardiovasc Magn Reson 8:453-460

16. van der Wall EE, van Dijkman PR, de Roos A et al (1990) Diagnostic significance of gadolinium-DTPA (diethylenetriamine penta-acetic acid) enhanced magnetic resonance imaging in thrombolytic treatment for acute myocardial infarction: its potential in assessing reperfusion. Br Heart $\mathrm{J}$ 63:12-17

17. van Dijkman PR, van der Wall EE, de Roos A et al (1991) Acute, subacute, and chronic myocardial infarction: quantitative analysis of gadolinium-enhanced MR images. Radiology 180:147-151

18. Bax JJ, Lamb H, Dibbets P et al (2000) Comparison of gated single-photon emission computed tomography with magnetic resonance imaging for evaluation of left ventricular function in ischemic cardiomyopathy. Am J Cardiol 86:1299-1305

19. van Rugge FP, van der Wall EE, Bruschke AV (1992) New developments in pharmacologic stress imaging. Am Heart J 124:468-485
20. van Rugge FP, Holman ER, van der Wall EE, de Roos A, van der Laarse A, Bruschke AV (1993) Quantitation of global and regional left ventricular function by cine magnetic resonance imaging during dobutamine stress in normal human subjects. Eur Heart J 14:456-463

21. Langerak SE, Vliegen HW, de Roos A et al (2002) Detection of vein graft disease using high-resolution magnetic resonance angiography. Circulation 105:328-333

22. Silva C, Moon JC, Elkington AG, John AS, Mohiaddin RH, Pennell DJ (2007) Myocardial late gadolinium enhancement in specific cardiomyopathies by cardiovascular magnetic resonance: a preliminary experience. J Cardiovasc Med 8:1076-1079

23. Mahrholdt H, Wagner A, Deluigi CC et al (2006) Presentation, patterns of myocardial damage, and clinical course of viral myocarditis. Circulation 114:1581-1590

24. Sato Y, Matsumoto N, Kunisama $T$ et al. Myocardial fibrosis in a patient with apical hypertrophic cardiomyopathy detected by delayed-enhanced magnetic resonance imaging. Int J Cardiol 2007 [Epub ahead of print]

25. Efthimiadis GK, Spamos GP, Gianakoulas G et al (2008) Hypertrophic cardiomyopathy with late enhancement of the non-hypertrophied left ventricular segments. Hellenic J Cardiol 49:114-116 